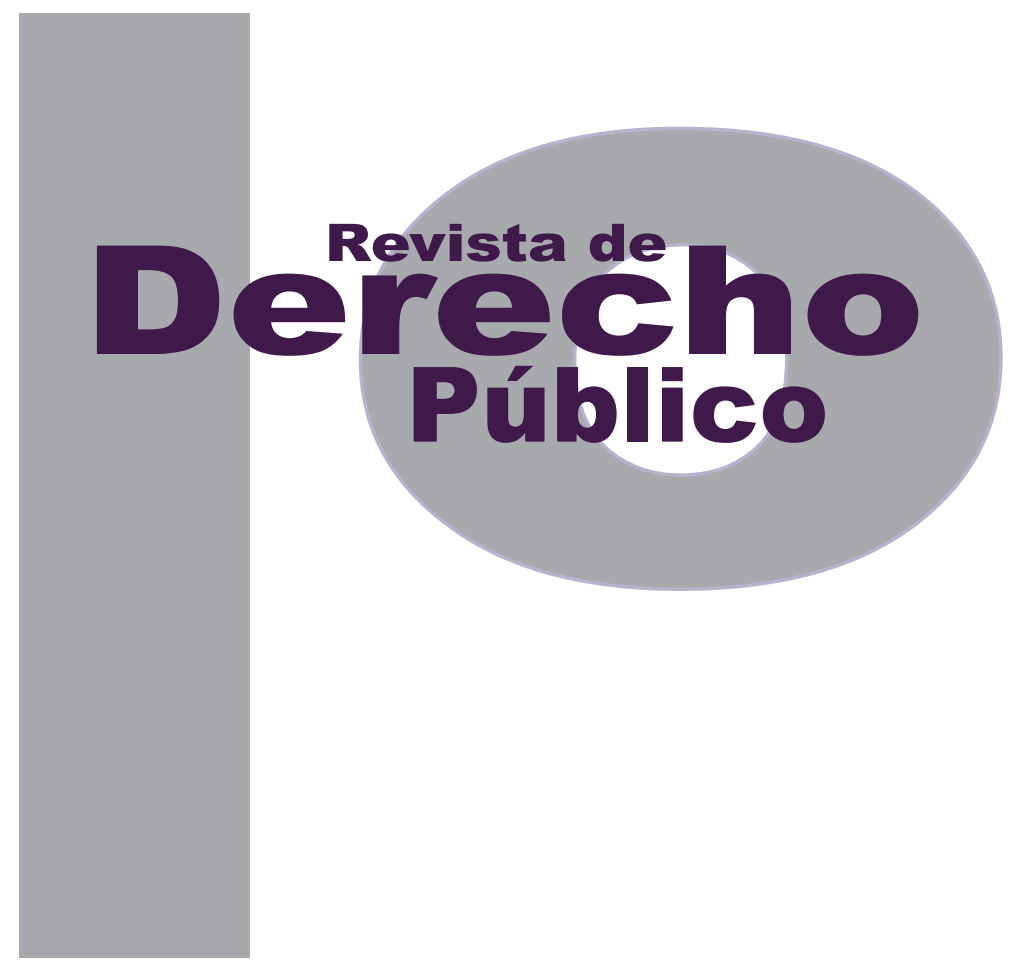

\title{
LOS BIENES INCORPORALES ESTATALES
}

\author{
Adriana Camacho Ramírez \\ Francisco TERnERA BARRIOS
}

Universidad de los Andes

Facultad de Derecho

Revista de Derecho Público N. ${ }^{\circ} 28$

Enero - Junio de 2012. ISSN 1909-7778 


\title{
Los bienes incorporales estatales
}

\author{
Adriana Camacho Ramírez ${ }^{1}$ \\ Francisco Ternera Barrios ${ }^{2}$
}

\section{RESUMEN}

La propiedad intelectual se reconoce sobre bienes o cosas incorporales. Hablamos de cosas que no están dotadas de materia y, por ello, no ocupan espacio físico alguno. Sobre esta variedad de cosas el Estado también puede reconocerse como propietario. En una palabra, pretendemos estudiar, entre otros temas, las obras de ingenio, las marcas y los otros signos distintivos del Estado.

Palabras clave: Obras de ingenio, marcas, signos distintivos, propiedad intelectual, Estado.
The intellectual property recognizes on incorporeal goods. We spoke of goods that are not equipped with matter and, for that reason, do not occupy physical space some. On this variety of things the State also can be recognized like proprietor. In a word, we try to study, among other subjects, the trademarks and others distinctive signs and original works of the State.

Keywords: Original works, trademarks, distinctive signs, intellectual property, State.

1 Abogada de la Universidad del Rosario. Doctorado en Jurisprudencia en la Universitá degli Studi di Milano (Italia). Maestría en Derecho Laboral y Administración del Personal en la Universitá Cattolica del Sacro Cuore di Milano (Italia). Profesora de Derecho Comunitario Laboral y Derecho Comparado Laboral. adrianacamachoramirez@yahoo.it

2 Abogado de la Universidad del Rosario. Maestría en Derecho Privado General y en Derecho Civil de las Obligaciones, en la Universidad de París II. Doctor de la Universidad Alfonso X de Madrid. Profesor de Propiedad y Derechos Reales. franciscoternera@yahoo.com 


\section{SUMARIO}

Introducción - I. DOMINIO INTELECTUAL PÚBLICO: HISTORIA DE UN FALSO CONCEPTO DE PROPIEDAD - A. Referencias al denominado dominio público - B. Alcance jurídico de la expresión - II. BIENES FISCALES INCORPORALES: PROPIEDAD INTELECTUAL ESTATAL - $A$. Obras de ingenio estatales - $B$. Incorporales industriales estatales - III. CONCLUSIONES - Bibliografía. 


\section{Introducción}

Para cumplir con sus funciones, las entidades estatales deben apoyarse en medios o instrumentos jurídicos. Piénsese, por ejemplo, en los funcionarios, empleados y contratistas de la administración; en los edificios, automóviles y dineros de los cuales se sirven las entidades estatales, entre muchos otros.

Respecto de estos últimos, la normativa ofrece a las entidades estatales -en general a todos los sujetos de derecho- la titularidad de los denominados derechos patrimoniales: derechos reales y personales. En el universo de los derechos patrimoniales se destaca la propiedad o dominio. Con ésta se recoge el concepto mismo de riqueza: todo aquello que, potencialmente, puede satisfacer una necesidad directa o indirecta del hombre. ${ }^{2}$ Engloba los principales poderes directos que se pueden tener sobre un bien: uso, goce y disposición (plena potestas). Confiere a su titular el señorío total sobre la cosa. Desde luego, estos poderes pueden ser objeto de ciertas restricciones legales y convencionales. ${ }^{3}$

La propiedad o dominio se reconoce sobre bienes materiales (muebles e inmuebles). También,

2 Según la definición de "riqueza" ofrecida por Alfred Marshall en sus Principios de economía política. Citado por Henry George. La ciencia de la economía política. Traducido por Baldomero Argente. Madrid: Librería española y extranjera, 1922, p. 167.

3 El célebre historiador Michel Villey nos regala una bellísima referencia al respecto. En 1323, con la bula Ad conditorem canonum, el papa Juan XXII le explicó a la comunidad franciscana que el Papado no podía considerarse propietario de unos terrenos respecto de los cuales se le había reconocido un usufructo perpetuo a la mencionada comunidad. Es decir, no teniendo el Papado la vocación a la plenitud de los poderes sobre los terrenos, mal podría reconocerse como propietario. Villey, Mihel. La formation de la pensée juridique moderne. París: Puf, 2006, p. 245. bajo la expresión propiedad intelectual, la normativa permite un dominio sui generis sobre los bienes inmateriales (v. gr. obras de ingenio e incorporales industriales).

A propósito de la normativa de la propiedad intelectual, podrían citarse, entre otros, los siguientes instrumentos: arts. 61 Constitución Nacional (CN), 670 Código Civil (CC); Ley 23 de 1982; Decisiones 351 de 1993 y 486 de 2000 de la Comunidad Andina de Naciones (CAN); Acuerdo sobre Patentes y Privilegios de Invención (Ley 18 de 1913); Convención Interamericana sobre Derechos de Autor en Obras Literarias, Científicas y Artísticas (Ley 6 de 1970); Convenio de Berna para la Protección de las Obras Literarias y Artísticas (Ley 33 de 1987); Convenio de París para la Protección de la Propiedad Industrial (Ley 178 de 1994); Acuerdo sobre los Aspectos de los Derechos de Propiedad Intelectual Relacionados con el Comercio (Ley 170 de 1994); Convenio sobre la Diversidad Biológica (Ley 165 de 1994); Tratado sobre el Derecho de Marcas (Ley 1343 de 2009); Protocolo del Arreglo de Madrid (Ley 1455 de 2011); Acuerdo de promoción comercial entre la República de Colombia y los Estados Unidos de América; y el Protocolo Modificatorio al Acuerdo de Promoción Comercial ColombiaEstados Unidos (leyes 1143 y 1166 de 2007).

En las siguientes líneas hablaremos de esta última variedad de propiedad. Más concretamente, nos ocuparemos del reconocimiento de este derecho de propiedad sui generis en el patrimonio de las entidades estatales. 
Tradicionalmente, los operadores jurídicos han distinguido dos diferentes tipos de propiedad estatal: dominio de las entidades estatales sobre los bienes fiscales (v. gr. edificios, baldíos, vacantes, etc.), por un lado, y propiedad sobre los bienes públicos (v. gr. bienes de uso público, parques naturales, patrimonio arqueológico y bienes del territorio (arts. 674 CC; 63, 72 y 102 $\mathrm{CN})^{4}$, por otro.

Una primera aproximación al concepto de bien público la encontramos en Gayo, quien identificaba dos variedades de cosas en el derecho humano: las públicas y las privadas (publicae y priuatae). ${ }^{5}$ Justiniano distinguía las res in nostro patrimonio, que podían ser del dominio de una persona privada, y las res extra nostrum patrimonium, que no podían pertenecer a ningún particular. ${ }^{6}$ Por su parte, las res publicae o las res extra nostrum patrimonium estaban compuestas por las res in usu publico, cuya única vocación era servir al interés general, y por las

4 Colombia. Consejo de Estado, Sala de Consulta y Servicio Civil, Sentencia del 5 de diciembre de 2002, Rad. 1469; Consejo de Estado, Sala de lo Contencioso Administrativo, Sección Primera, Sentencia del 12 de mayo de 1995, Rad. 3158, M.P. Rafael Ariza M.; Consejo de Estado, Sala de lo Contencioso Administrativo, Sección Primera, Sentencia del 6 de febrero de 2003, Rad. 58045, M.P. Olga Inés Navarrete Barrero; Consejo de Estado, Sala de lo Contencioso Administrativo, Sección Cuarta, Sentencia del 8 de mayo de 2008, Exp. 15448, M.P. Héctor Romero D.; Consejo de Estado, Sala de lo Contencioso Administrativo, Sección Primera, Sentencia del 6 de julio de 2000, Exp. 5303, M.P. Juan Alberto Polo; Corte Constitucional, Sentencia T- 50 de 1995, M.P. Alejandro Martínez Caballero; Corte Constitucional, Sentencia C-189 de 2006, M.P. Rodrigo Escobar G.

5 Gayo. Instituciones, 107. Comentario segundo. Madrid: Cívitas, 1985, pp. 10-11. Con los romanos, el concepto de lo público se dotó de personalidad jurídica. Nos referimos a las universitates rerum, asociaciones de personas que tenían reconocimiento jurídico y patrimonio. A este género pertenecían el fiscus, civitates, coloniae, municipia, etc. Véase: Paul F., Girard. Manuel élémentaire de droit romain. París: A. Rousseau, 1918, p. 241.

6 Justiniano. Instituciones, 81, Libro segundo, título I. Bogotá: Facultad de Derecho, 2006. De esta clasificación están excluidas las cosas comunes a todos, como el aire, el mar, los ríos, etc. (res communia). res in pecunia populi o res in patrimonio fisci, cuya destinación no estaba directamente comprometida con el interés general. Al lado de esta variedad de bienes, encontramos los bona vacantia, cuya vocación era ser adjudicados a los súbditos. ${ }^{7}$

La primera propiedad, la denominada propiedad privada del Estado, se caracteriza por acoger las características de la propiedad clásica u ortodoxa: un derecho real pleno, exclusivo, perpetuo, autónomo e irrevocable. ${ }^{8}$ Se trata de un derecho pleno, exclusivo, perpetuo, autónomo e irrevocable.

De manera clara se identifican los dos elementos del derecho real de dominio: un elemento principal representado por el haz de poderes directos sobre el bien y, como elemento accesorio, una serie de vínculos-obligaciones impuestos sobre el titular respecto de otros sujetos determinados. Su titular ostenta con exclusividad e independencia los poderes de la propiedad. Así, por ejemplo, sobre los fiscales adscritos al servicio las entidades estatales ejercen un claro ius utendi, al someterlos a una destinación específica; también, a través de contratos no traslaticios de dominio, como el arrendamiento, estos bienes pueden producir frutos -ius fruendi-. Respecto del ius disponendi, afirmamos que la propiedad privada es enajenable. Por consiguiente, con ciertas excepciones legales, también puede ser embargable. Así mismo, sobre el

7 Diferentes de los ager occupatorius: terrenos públicos explotados por meros tenedores, que debían pagar una retribución o vectigal.

8 Importantes "parecidos de familia" encontramos entre los fiscales y los denominados "propios" mencionados en las Partidas (v. gr. P. 3, 29, 7) 
dueño se imponen algunas obligaciones propter rem; por ejemplo, las entidades públicas propietarias de inmuebles fiscales pueden resultar obligadas al pago de la contribución de valorización (art. 237 del Decreto 1333 de 1986 col.). También, por ser propietarias de inmuebles fiscales en un determinado municipio, entidades estatales como los establecimientos públicos, las empresas industriales y comerciales del Estado y las sociedades de economía mixta del orden nacional pueden ser gravadas con el impuesto predial en favor del respectivo municipio (art. 194 del Decreto 1333 de 1986 col.).

Por su lado, la propiedad pública debe entenderse como un derecho inalienable, imprescriptible e inembargable (arts. 63 y $72 \mathrm{CN}$ ). Se trata de un verdadero derecho patrimonial, que se ofrece a las personas jurídicas de derecho público, cuyo ius utendi o poder de uso se extiende a todos los habitantes. En efecto, respecto de estos bienes públicos las entidades estatales pueden ejercer un auténtico poder de goce. Piénsese, por ejemplo, en los actos precarios que permiten la ocupación transitoria de una plaza, contra el pago de una tasa ${ }^{9}$ o el otorgamiento de un contrato de concesión que le permite a un particular la prestación de un servicio relacionado con un bien de uso público. Por lo demás, en desarrollo de estos contratos puede establecerse una contraprestación. ${ }^{10}$ Incluso, siempre que

9 Colombia. Consejo de Estado, Sala de lo Contencioso Administrativo, Sección Primera, Sentencia del 6 de febrero de 2003, Rad. 58045, M.P. Olga Inés Navarrete Barrero.

10 Véase: Colombia. Consejo de Estado, Sala de lo Contencioso Administrativo, Sección Primera, Sentencia del 16 de noviembre de 2000, M.P. Olga Inés Navarrete Barrero. Igualmente: Colombia. Consejo de Estado, Sala de lo Contencioso Administrativo, Sección Primera, Sentencia del 3 de agosto de 2000, Rad. 6264, M.P. Juan se respete la afectación del bien de uso público, se ha permitido la celebración de contratos de arrendamiento que dan lugar al pago de un canon. ${ }^{11}$ La propiedad pública que se reconoce sobre bienes del territorio, como el espacio electromagnético, puede igualmente comprender cierto ejercicio del ius fruendi (art. $102 \mathrm{CN}$ ), por ejemplo, con las concesiones de televisión, de telefonía móvil, etc. ${ }^{12}$

En los dos casos se trata de un derecho de propiedad, esto es, un conjunto de poderes directos sobre un bien que, por lo demás, se engloba en tres categorías jurídicas: ius utendi, ius fruendi y ius disponendi abutendi.

Estas dos variedades de propiedad estatal se reconocen sobre los bienes materiales o corporales. Empero, respecto de los incorporales o inmateriales, aquellos que no están dotados de materia ni ocupan espacio físico alguno,

Alberto Polo F. Esta contraprestación puede estar materializada en dinero, obras, servicios, etc., prestados por el concesionario.

Colombia. Consejo de Estado, Sala de lo Contencioso Administrativo, Sección Tercera, Sentencia del 22 de junio de 2006, Exp. 25000-2327-000-2003-02077-01, M.P. María Elena Giraldo Gómez. Igualmente: Colombia. Consejo de Estado, Sala de lo Contencioso Administrativo, Sección Primera, Sentencia del 23 de marzo de 2000, Rad. 5504, M.P. Manuel Urueta A. Sin embargo, en numerosos fallos se ha asegurado que este tipo de contratos respecto de los bienes públicos adolecen de objeto ilícito. Véanse: Colombia. Consejo de Estado, Sala de lo Contencioso Administrativo, Sentencia del 16 de febrero de 2001, M.P. Alier E. Hernández E.; Jurisprudencia y Doctrina, t. XXX, N. ${ }^{\circ} 352$, abril de 2001, p. 669; Colombia. Consejo de Estado, Sala de lo Contencioso Administrativo, Sección Tercera, Sentencia del 22 de abril de 2004, Rad. 16245, M.P. Ricardo Hoyos Duque; Colombia. Consejo de Estado, Sala de lo Contencioso Administrativo, Sección Cuarta, Sentencia del 28 de enero de 2000, Rad. 2679, M.P. Daniel Manrique G.

12 Para ilustrar, algunas cifras relacionadas con la concesión del espectro electromagnético: en 1994 los particulares le pagaron al Estado 973.442 millones de pesos. El Tiempo, 14 de abril de 1994.

Otra cifra: el precio base del posible tercer y nuevo canal nacional, según el pliego de condiciones de la licitación, es de 103.409 millones de pesos. Véase: Colombia. Tribunal de Cundinamarca, Sección Cuarta, Sentencia del 9 de diciembre de 2011. 
¿las entidades estatales también ejercen una propiedad privada y pública? A continuación nos concentraremos en dar respuesta a este cuestionamiento.

En una primera parte hablaremos del denominado dominio intelectual público de las entidades estatales. Sobre el particular, precisaremos que se trata de un falso concepto de propiedad o dominio.

En una segunda parte comentaremos un verdadero derecho de propiedad intelectual estatal que se reconoce sobre algunos fiscales incorporales.

\section{DOMINIO INTELECTUAL PÚBLICO: HISTORIA DE UN FALSO CONCEPTO DE PROPIEDAD}

Respecto del dominio público sobre incorporales, se consagran numerosas referencias en nuestra normativa (numeral A). No obstante, todas estas reseñas normativas no se pueden reconocer como verdaderos derechos de propiedad intelectual de las entidades estatales (numeral B).

\section{A. Referencias al denominado dominio público}

El legislador civil estableció que la propiedad pública estatal se predica respecto de los bienes de uso público (art. 674 CC). Además, el constituyente propuso nuevos ejemplos de propiedad pública, como aquella que se reconoce sobre los inmuebles estatales ubicados en parques naturales o sobre el patrimonio arqueológico (art. 63 $\mathrm{CN}$ ). Esta propiedad o dominio público se define como un derecho inalienable, imprescriptible e inembargable (arts. 63 y $72 \mathrm{CN}$ ).

Ahora bien, téngase claro que estas características de la propiedad pública no desdibujan el carácter "patrimonial” de este derecho.

Primero, estas tres características no tienen un carácter absoluto. Efectivamente, tales bienes pueden ser objeto de desafectación, con la cual se modifica su régimen jurídico. Así las cosas, el bien público se convierte en bien fiscal. ${ }^{13}$

Segundo, algunos derechos de propiedad de los particulares han sido también limitados con estas características de inalienabilidad, imprescriptibilidad e inembargabilidad. A modo de ejemplo piénsese en lo siguiente: son inalienables las propiedades particulares ubicadas en parques naturales (art. 13 de la Ley 2 de 1959) ${ }^{14}$; son imprescriptibles aquellos bienes particulares ofrecidos al uso general de la comunidad (art. $676 \mathrm{CC})^{15} \mathrm{y}$, respecto de la imprescriptibilidad, podríamos recordar que no es

13 Véase: Colombia. Corte Constitucional, Sentencia T-150 de 1995, M.P. Alejandro Martínez C.

14 Por lo demás, otros derechos reales como el de uso y habitación son siempre inalienables (Art. 878 CC). Véase: Colombia. Corte Constitucional, Sentencia C-189 de 2006, M.P. Rodrigo Escobar G.

15 Véase: Colombia. Corte Suprema de Justicia, Casación Civil, Sentencia del 14 de junio de 1988. Jurisprudencia y doctrina, t. XVII, $n^{\circ} 200$, agosto de 1988, p. 619; Corte Suprema de Justicia, Casación Civil, Sentencia del 26 de abril de 1995, G. J, n² 26, p. 17; Corte Suprema de Justicia, Casación Civil, Sentencia del 29 de julio de 1999, exp. 5074, M.P. Jorge A. Castillo R. Finalmente, Consejo de Estado, Sala de lo Contencioso Administrativo, Sentencia del 6 de febrero de 2003, M.P. Olga Inés Navarrete B. 
embargable el patrimonio de familia (art. 1 de la Ley 70 de 1931). ${ }^{16}$

Tercero, el carácter de "inalienable", "imprescriptible" e "inembargable" no es sinónimo de "inexplotable". En efecto, si se trata de bienes como los de uso público, las entidades públicas pueden percibir lucro a través de actos jurídicos que no comprometen el derecho de propiedad: actos que permiten la ocupación transitoria de una plaza, contra el pago de una tasa, ${ }^{17}$ o el otorgamiento de un contrato de concesión que le permite a un particular la prestación de un servicio relacionado con un bien de uso público ${ }^{18}$.

Vemos, entonces, cómo esta propiedad pública tiene importantes "parecidos de familia" con la propiedad privada del Estado mismo y de los particulares. Principalmente, puede ofrecer beneficios pecuniarios al dominus, tales como el poder de goce o explotación.

16 Así mismo, el único bien inmueble urbano o rural perteneciente a la mujer cabeza de familia se constituye en patrimonio familiar inembargable (art. 1 de la Ley 861 de 2003).

17 Colombia. Consejo de Estado, Sala de lo Contencioso Administrativo, Sección Primera, Sentencia del 6 de febrero de 2003, Rad. 58045, M.P. Olga Inés Navarrete Barrero.

18 En desarrollo de estos contratos puede establecerse una contraprestación. Véase: Colombia. Consejo de Estado, Sala de lo Contencioso Administrativo, Sección Primera, Sentencia del 16 de noviembre de 2000, M.P. Olga Inés Navarrete. Igualmente: Colombia. Consejo de Estado, Sala de lo Contencioso Administrativo, Sección Primera, Sentencia del 3 de agosto de 2000, Rad. 6264, M.P. Juan Alberto Polo F. Esta contraprestación puede estar materializada en dinero, obras, servicios, etc., prestados por el concesionario. También se permiten contratos de arrendamiento que dan lugar al pago de un canon, siempre que se respete la afectación del bien de uso público. Véase: Colombia. Consejo de Estado, Sala de lo Contencioso Administrativo, Sección Tercera, Sentencia del 22 de junio de 2006, Exp. 2500023-27-000-2003-02077-01, M.P. María Elena Giraldo G. Igualmente: Consejo de Estado, Sala de lo Contencioso Administrativo, Sección Primera, Sentencia del 23 de marzo de 2000, Rad. 5504, M.P. Manuel Urueta.
Por otro lado, la génesis de la protección a los autores la encontramos en la Ley 1 del 10 de mayo de 1834, que señalaba: “[e]l Estado protegerá la propiedad intelectual o de obras o composiciones literarias, mapas, planos, pinturas o dibujos y obras musicales." La protección al autor se materializaba, principalmente, así: se ofrecía un privilegio al autor -residente en el país-, por un término de quince años, prorrogables por otros quince años. Actualmente, los derechos de propiedad sobre la obra, como se establece en las leyes 23 de 1982 y 44 de 1993, son alienables, renunciables y están sometidos a la prescripción extintiva. El artículo 21 de la misma ley nos precisa que el derecho de dominio se debe reconocer durante toda la vida del autor y después de su fallecimiento disfrutarán de él quienes legítimamente los hayan adquirido, por el término de ochenta años.

En materia de bienes inmateriales, en la normativa se ha acogido la sugestiva expresión dominio público. Por ejemplo, respecto de las obras de ingenio, en algunos pasajes de la Ley 23 de 1982 (v. gr. arts. 14, 16, 23 y 30 ídem). En el artículo 187 de esta ley se establece que pertenecen al dominio público las obras cuyo periodo de protección esté agotado y las obras folclóricas y tradicionales de autores desconocidos.

En el primer caso, nos informa el art. 21 de la Ley 23 de 1982 que el derecho de dominio se reconoce durante toda la vida del autor-propietario. Después “de su fallecimiento disfrutarán de él quienes legítimamente los hayan adquirido, por el término de ochenta años". Ahora, si no hubiere causahabientes, la obra será de 
dominio público desde el fallecimiento del autor (art. 23 de la Ley 23 de 1982).

En el segundo caso, por un lado, se podrían citar las manifestaciones incluidas en la lista representativa de patrimonio cultural inmaterial. Respecto de estas últimas, en los términos del art. 1 lit. b) de la Ley 1185 de 2008, se establece un régimen especial de salvaguardia, protección, sostenibilidad y divulgación. ${ }^{19}$ Por otro lado, se encierran las obras artísticas que hacen parte del patrimonio arqueológico de la nación.

Sin embargo, ¿podría afirmarse que con esta expresión dominio público se reconoce un auténtico derecho de propiedad del Estado sobre estos inmateriales? En otras palabras, ¿este dominio público ofrece al Estado poderes directos y pecuniarios sobre los inmateriales referenciados? En el siguiente segmento daremos respuesta a estas preguntas.

\section{B. Alcance jurídico de la expresión}

Consideramos que esta falsa versión de "dominio público" no es un verdadero derecho de propiedad, esto es, un derecho que ofrezca poderes directos, estimables en dinero, sobre un bien. Pensamos que estos bienes incorporales deben identificarse como auténticos bienes res communes: bienes que no son apropiables por ningún sujeto de derecho.

Para nosotros, este mal denominado dominio público se engloba dentro del concepto no

19 Véase también: Colombia. Corte Constitucional. Sentencia C-668 de 2005, M.P. Álvaro Tafur G. patrimonial de dominio eminente. En ejercicio de este dominio eminente el Estado no sólo puede vigilar los bienes públicos que integran su patrimonio sensu stricto sino que también ejerce poderes públicos de policía respecto de los bienes de la esfera privada. Por ejemplo, por mandato constitucional debe velar por la protección de la integridad del espacio público ${ }^{20}$ (art. $82 \mathrm{CN}$ ), puede extinguir los derechos de dominio adquiridos por los particulares de manera ilícita o en desconocimiento de la función social de la propiedad (arts. 34 y $58 \mathrm{CN}$ ), imponer medidas que consultan el interés general como la expropiación respecto de los derechos patrimoniales de los asociados (art. $58 \mathrm{CN}$ ), entre otros.

Respecto de las obras de ingenio, se autoriza en la normativa la expropiación de la propiedad sobre la obra, incluso antes de la terminación del derecho de propiedad, siempre que la obra se repute como de gran valor cultural y de interés social o público. Naturalmente, al expropiado deberá pagársele una indemnización (arts. 58 CN y 80 de la Ley 23 de 1982) $)^{21}$.

20 El concepto de "espacio público" es más amplio que el de "dominio público". En efecto, con él también se engloban bienes del patrimonio de los particulares (v. gr. los elementos arquitectónicos de los inmuebles privados destinados a la satisfacción de necesidades urbanas (Art. 5 de la Ley 9 de 1989)). La característica fundamental de los bienes que integran el espacio público es su afectación al interés general. De esta manera, los derechos y los intereses privados "si entran en conflicto con el interés público deben subordinarse a éste". Colombia. Corte Constitucional. Sentencia SU-360 de 1999, M.P. Alejandro Martínez C.

Señala la jurisprudencia que un control ineficiente del espacio público puede generar "la perturbación grave de la tranquilidad, la seguridad, la salubridad y moralidad públicas" Colombia. Corte Constitucional, Sentencia T-490 de 1999, M.P. Vladimiro Naranjo M.

21 Por ejemplo, con la Ley 33 de 1920 se adoptó como parte del Himno Nacional de Colombia la música de Oreste Síndici. En esta misma ley se ordenó un eventual reajuste de la indemnización a favor de los causahabientes del reconocido compositor. 
En materia de propiedad industrial encontramos un ejemplo clásico del ejercicio de este dominio eminente: la imposición de licencias obligatorias sobre patentes de invención. Estas últimas pueden ser impuestas en tres casos: como medida expropiatoria parcial, como sanción, y como herramienta de explotación de otra invención. En el primero, la licencia obligatoria se presenta como una medida expropiatoria parcial, motivada por razones de interés público, emergencia o de seguridad nacional (art. 65 de la Decisión 486 de 2000 de la CAN). Como sanción la licencia obligatoria penaliza la inexplotación de la patente o las prácticas que afecten la libre competencia (arts. 61, 66 de la Decisión 486 de 2000 de la CAN y 5 del Convenio de París). Finalmente, como herramienta de explotación, cuando una invención requiera necesariamente del empleo de otra, en beneficio de esta segunda se puede ofrecer la licencia de explotación de la primera (art. 67 ídem).

De igual manera, la propiedad marcaria está sometida a estos poderes de policía derivados del dominio eminente. Por consiguiente, el derecho mismo de propiedad sobre la marca puede ser objeto de extinción, siempre que durante un término de tres años consecutivos, sin justificación alguna, no se hubiese utilizado el signo marcario (art. 165 de la Decisión 486 de 2000).

En suma, respecto de nuestra materia, concluimos que el denominado dominio público tiene que definirse como un derecho extrapatrimonial del Estado. Sin duda, debe admitirse que el legislador incurrió en un yerro cuando se sirvió de la voz "dominio" para dar cuenta de un instituto extraño al patrimonio del Estado. Empero, ¿el dominio que se reconoce sobre ciertos bienes fiscales incorporales también es un derecho extrapatrimonial? Dicho en plata blanca, ¿estaríamos igualmente ante un empleo abusivo de la palabra "dominio"? Ocupémonos entonces de estas nuevas preguntas.

\section{BIENES FISCALES INCORPORALES: PROPIEDAD INTELECTUAL ESTATAL}

La propiedad privada estatal se reconoce respecto de los denominados bienes fiscales. Grosso modo, podría sostenerse que esta propiedad ostenta las características de la propiedad clásica u ortodoxa de los particulares: es un derecho pleno, exclusivo, perpetuo, autónomo e irrevocable. Hablamos, a guisa de ejemplo, de todos los signos distintivos, nuevas creaciones y obras de ingenio de propiedad de las entidades estatales (arts. 20, 91, 92 de la Ley 23 de 1982; 50, 128 y 152 de la Decisión 486 de 2000 de la CAN).

La propiedad intelectual estatal se consagra respecto de las obras de ingenio (numeral $A$ ) y los incorporales industriales estatales (numeral B).

\section{A. Obras de ingenio estatales}

Sobre las obras de ingenio literarias, artísticas y científicas se reconocen los denominados derechos de autor. ${ }^{22}$ Los titulares de los derechos de

22

El Estatuto de la Reina Ana, del 10 abril de 1710, es la primera norma de protección de los intereses del autor de la cual se tenga noticia. "(...) That from and after the tenth day of April, one thousand seven 
autor son las personas naturales creadoras de sus respectivas obras. ${ }^{23}$ Puntualmente se consagran dos variedades de derechos de autor: derechos extrapatrimoniales y patrimoniales.

\section{Los derechos extrapatrimoniales o morales tie-} nen rango constitucional. Se reconocen como derechos "inalienables, irrenunciables, indivisibles y de duración ilimitada, pues están destinados a proteger los intereses intelectuales del

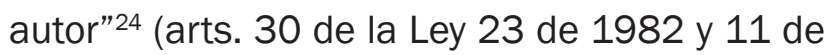
la Decisión 351 de 1993 de la CAN; v. gr., el de-

hundred and ten, the author of any book or books already printed, who hath not transferred to any other the copy or copies of such book or books, share or shares thereof, or the bookseller or book-sellers, printer or printers, or other person or persons, who hath or have purchased or acquired the copy or copies of any book or books, in order to print or reprint the same, shall have the sole right and liberty of printing such book and books for the term of one and twenty years, to commence from the said tenth day of April, and no longer; and that the author of any book or books already composed and not printed and published, or that shall hereafter be composed, and his assignee, or assigns, shall have the sole liberty of printing and reprinting such book and books for the term of fourteen years, to commence from the day of the first publishing the same (...)" Disponible en: <http://www.copyrighthistory. com/anne.html>.

En Francia, con palabras elocuentes para la historia, el abogado Marion expresaría: el hombre es señor "de ce qu'il fait, invente et compose". Transcripción, realizada por Anne Latournerie, publicada en la revista electrónica Multitudes. Disponible en http://multitudes.samizdat.net/article.php3?id_article $=168$

Se reclama que la obra se produzca en desarrollo de un plan ofrecido por la persona que la encargó. Es decir, se exige que la obra de ingenio esté directamente relacionada con la causa-fin del encargo. En este caso, el autor o los autores solamente percibirán los honorarios pactados en el respectivo contrato, siempre conservando los derechos extrapatrimoniales o morales mencionados en los literales a) y b) del Art. 30 de la Ley 23 de 1982.

23 "El principio general reconoce como autor a la persona natural que crea la obra, a la cual se le atribuye la titularidad originaria de la misma; partiendo de este presupuesto las personas jurídicas, en cuanto carecen de capacidad creadora, no pueden ser titulares originarios de los derechos de autor que de ellas se derivan, cosa distinta es que lo sean las personas naturales que las constituyen". Colombia. Corte Constitucional, Sentencia C-276 de 1996, M.P. Julio César Ortiz G.

24 Colombia. Corte Constitucional, Sentencia C-276 de 1996, M.P. Julio César Ortiz G. recho a la paternidad sobre la obra ${ }^{25}$ y a la conservación de su integridad ${ }^{26}$ ).

Por supuesto, respecto de la obra también se reconocen derechos patrimoniales como la propiedad. Este derecho de propiedad sui generis sobre la obra de ingenio surge con su creación (art. 9 de la Ley 23 de 1982). Ahora, a través de mecanismos como la tradición y la sucesión mortis causa, el autor puede transferir o transmitir su derecho sobre la obra a otra persona natural o jurídica, incluso a una entidad estatal (arts. 182, 183 y 193 de la Ley 23 de 1982).

Como nota destacada, en la normativa se consagran presunciones legales de tradición del derecho de propiedad sobre la obra. En nuestro caso concreto podríamos hablar de todas las obras de ingenio encargadas por las entidades estatales a terceros, a través de contratos de

25 Este derecho moral se le reconoce incluso al autor que bajo contrato presta sus servicios para otra persona natural o jurídica. Consúltese: Rengifo, E. (2003). Propiedad intelectual. El moderno derecho de autor. Bogotá: Universidad Externado, p. 128.

Nota destacada de los morales merece el derecho a la paternidad de la obra. La doctrina así lo ha calificado: “(...) el derecho de paternidad constituye el eje medular de toda la materia de propiedad intelectual $y$, por otra parte, se encuentra íntimamente relacionado con el <derecho al nombre>> anteriormente considerado, pues es obvio que si la divulgación de la obra se ha realizado bajo el propio nombre del autor, la paternidad de la obra difícilmente puede ser puesta en duda y se encuentra garantizada con la propia divulgación de la obra". Lasarte, Carlos. Propiedad y derechos reales de goce, p. 232.

26 Por ejemplo, cuando a través de modificaciones se vulnera la reputación de la obra misma y de su autor (art. 11 de la Decisión 351 de 1993 de la CAN). Ahora, como excepción de este derecho moral podría mencionarse el siguiente caso: siempre que se trate de un proyecto arquitectónico, el autor "no podrá impedir que el propietario introduzca modificaciones en él, pero tendrá la facultad de prohibir que su nombre sea asociado a la obra alterada" (art. 43 de la Decisión 351 de 1993 de la CAN). En el mismo sentido, véase: Anónimo. (2000). "Copyrightvisual Artists Rights Act”. Harvard Law Review. t. 109, n 8, p. 2110. 
prestación de servicios (art. 20 de la Ley 23 de $1982)^{27}$.

También se establece que las obras de ingenio, creadas por funcionarios o empleados públicos en cumplimiento de sus funciones legales y constitucionales, son de propiedad de las respectivas entidades estatales (art. 91 de la Ley 23 de 1982) ${ }^{28}$. Por lo demás, téngase en cuenta que las obras colectivas creadas dentro de un contrato laboral o civil, en las que sea imposible identificar el aporte individual de cada una de las personas naturales que en ellas contribuyen, tendrán por titulares de los derechos de autor a las entidades estatales por cuya cuenta y riesgo se realizan (art. 92 Ley 23 de 1982) 29.

La propiedad que se reconoce sobre las obras de ingenio es un derecho alienable, explotable y temporal. Primero, la entidad pública tiene el poder de disposición jurídica de su derecho de propiedad (arts. 182, 183 y 193 de la Ley 23 de 1982). Segundo, la entidad pública propietaria puede percibir los frutos civiles (arts. 717 CC; 76 de la Ley 23 de 1982; y 13 de la Decisión

27 Se reclama que la obra se produzca en desarrollo de un plan ofrecido por la persona que la encargó. Es decir, se exige que la obra de ingenio esté directamente relacionada con la causa-fin del encargo. En este caso, el autor o los autores solamente percibirán los honorarios pactados en el respectivo contrato, siempre conservando los derechos extrapatrimoniales o morales mencionados en los literales a) y b) del Art. 30 de la Ley 23 de 1982

28 Con excepción de las lecciones o conferencias de los profesores. En esta fórmula no se exige plan alguno presentado por la entidad estatal. Se incluyen todas las obras de ingenio, tanto las relacionadas con la causa-fin del encargo como las que tienen una relación indirecta con esta causa-fin. Se requiere simplemente que las obras se produzcan en cumplimiento de las funciones legales y constitucionales del respectivo funcionario o empleado público.

En este caso muy excepcional, tendría que reconocerse que la entidad estatal es, incluso, titular de los derechos morales o extrapatrimoniales sobre la obra.
351 de 1993 de la CAN), autorizando cualquier reproducción de la obra (v. gr. su edición ${ }^{30}$ ), traducción, adaptación, inclusión en película cinematográfica, videograma, video, fonograma $y$, en general, cualquier procedimiento o medio para su comunicación al público (v. gr. radiodifusión sonora o audiovisual). Tercero, el derecho de propiedad intelectual de la entidad estatal se somete a un plazo expreso y determinado: cincuenta años contados a partir de la realización, divulgación o publicación de la obra (art. 18 de la Decisión 351 de 1993 de la CAN).

El artículo 28 de la Ley 1450 de $2011^{31}$ regula el tema de la propiedad intelectual de obras creadas en cumplimiento de un contrato de prestación de servicios o de un contrato de trabajo: asigna al autor de la obra la titularidad de los derechos patrimoniales y morales sobre la misma; sin embargo, determina que "se presume, salvo pacto en contrario, que los derechos patrimoniales sobre la obra han sido transferidos al encargante o al empleador, según sea el caso, en la medida necesaria para el ejercicio de sus actividades habituales en la época de creación de la obra".

30 Con el denominado "contrato de edición" el autor o sus causahabientes permiten al editor, mediante compensación pecuniaria, el derecho de reproducción y distribución de la obra de ingenio. En este contrato se debe indicar: si se trata de una obra inédita, si la autorización es exclusiva, los plazos para la entrega del original y para su reproducción, el número de ediciones autorizadas, la cantidad de ejemplares de cada edición, la forma de distribución de los ejemplares, la remuneración del autor, entre otros aspectos (Art. 107 de la Ley 23 de 1982). Véase: España. Tribunal Supremo, Sentencia del 1 de febrero de 2005. Publicada en: Colección de propiedad intelectual. Madrid: Reus S.A., 2006, pp. 271 y ss.

31 Se trata del Plan Nacional de Desarrollo de Colombia 2010-2014, del presidente Juan Manuel Santos, denominado "Prosperidad para todos". 
Por lo tanto, podemos deducir de lo anterior, que el artículo referido también hace alusión a las relaciones contractuales en materia de derecho público, ya que no se identifica con singularidad el tipo de contrato de prestación de servicios o de contrato de trabajo al que se aplicaría esta reglamentación.

El Estado, como empleador o como encargante, podría ser en este caso el titular de dichos derechos patrimoniales, en la medida que con éstos se logre la realización de los fines que busca en interés general.

El Estado podría ser titular de dichos derechos en materia de propiedad intelectual e industrial, en cuanto se trate de un contrato de prestación de servicios, o que éste se presente como empleador en un contrato de trabajo; lo cual nos llevaría a pensar que excluye las relaciones laborales que se desprenden de una reglamentación legal, como a la que están sometidos los empleados públicos. Sin embargo, si por "contrato de trabajo" la ley se está refiriendo a simples relaciones laborales, debemos concluir que a los servidores públicos también podría aplicárseles esta reglamentación ${ }^{32}$.

32 De acuerdo con lo prescrito en el artículo 123 de la Constitución Política, el concepto de servidor público engloba varias figuras: "Son servidores públicos los miembros de las corporaciones públicas, los empleados y trabajadores del Estado y de sus entidades descentralizadas territorialmente y por servicios". Los empleados públicos son las personas naturales que ejercen sus funciones en un denominado empleo público, con la característica de la vinculación a través de un acto administrativo de nombramiento. Al contrario, la forma de vinculación de un trabajador oficial es a través de un contrato laboral que incluya las características que conocemos de la relación laboral, y que según el artículo 23 del Código Sustantivo del Trabajo son: la prestación del servicio de forma personal, la subordinación o dependencia y la remuneración.
El artículo 30 de la Ley 1450 de 2011 regula el tema de la transferencia de derechos de autor por "acto entre vivos", el cual limita el tiempo de la concesión del derecho a cinco (5) años si no se establece un término expreso. De igual manera, esta norma también podría aplicarse a contratos con el Estado.

En efecto, el titular de un derecho patrimonial de autor podría transferir dicha titularidad a una persona jurídica de derecho público. Asimismo, el artículo 31 de dicha ley establece que el Estado pueda ceder los derechos de propiedad intelectual que le correspondan a las partes en los proyectos de ciencia, tecnología e innovación adelantados con recursos del presupuesto nacional, según se establezca en el contrato, y salvo motivos de seguridad y defensa nacional. Lo cual ratifica la titularidad del derecho de bienes inmateriales en cabeza de entidades de derecho público.

\section{B. Incorporales industriales estatales}

Sobre los denominados incorporales industriales, signos distintivos (v. gr. marcas, lemas comerciales y nombres comerciales) y nuevas creaciones (p. ej. patentes y diseños industriales), se reconoce un derecho de dominio intitulado propiedad industrial. Las entidades estatales también pueden ser titulares de esta propiedad industrial. Concretamente, nos vamos a referir a dos incorporales industriales destacados: las marcas y las patentes de invención.

Por un lado, el dominio sui generis sobre la marca se reconoce desde su registro: un acto admi- 
nistrativo con el cual se autoriza a una persona para que explote económicamente un signo. ${ }^{33}$

En los términos del art. 152 de la Decisión 486 de 2000 de la CAN "el registro de una marca tendrá una duración de diez años contados a partir de la fecha de su concesión y podrá renovarse por períodos sucesivos de diez años". Agotado este término, más los seis meses del plazo de gracia, sin que se lleve a cabo la renovación del registro, el derecho de propiedad sobre la marca se extingue (art. 153 de la Decisión 486 de 2000 de la CAN). ${ }^{34}$

Por otro lado, las entidades públicas también pueden ser propietarias de las invenciones patentables. En términos generales, una invención es una construcción humana con la cual se resuelve un problema técnico. Respecto de algunas invenciones se reconoce un derecho de propiedad sui generis del inventor, también denominado derecho de patente. ${ }^{35}$

En el ámbito andino la solicitud de una patente debe contener varios elementos. Por ejemplo: petitorio, descripción, reivindicaciones, dibujos, resumen, entre otros (art. 26 de la Decisión

33 En relación con el registro, en el art. 41 del Acuerdo sobre los Aspectos de los Derechos de Propiedad Intelectual relacionados con el Comercio-ADPIC (anexo 1C del Convenio por el que se crea la OMC, firmado en 1994, aprobado por la Ley 170 de 1994) se establece que las decisiones finales sobre propiedad intelectual, proferidas por las autoridades administrativas, podrán ser revisadas por autoridad judicial.

Véase: Colombia. Corte Constitucional, Sentencia T-938 de 2004, M.P. Eduardo Montealegre L.

35 Conforme a los arts. 18 y 19 de la Decisión 486 de la CAN, la invención patentable debe ser novedosa. Además, debe tener nivel inventivo y aplicación industrial. Por lo demás, valga aclarar que el texto del TLC con EE.UU. parece borrar este último requisito: la invención no tiene que tener utilidad conocida (16.9 ídem).
486 de 2000 de la CAN). Entre estos requisitos formales se destacan las reivindicaciones: elemento fundamental de la solicitud por medio del cual se establece la materia de protección (art. 30 ídem). En otras palabras, con las reivindicaciones se delimita el objeto de la patente: la invención. El reconocimiento del derecho de patente tiene un plazo de duración de veinte años, contado a partir de la fecha de presentación de la respectiva solicitud (art. 50 de la Decisión 486 de 2000 de la CAN).

Por lo demás, téngase en cuenta que en el art. 80 de la Decisión 486 de 2000 de la CAN se establece que para mantener vigente la patente (incluso la solicitud de patente en trámite), se deben pagar las tasas anuales. También en el art. 60 ídem, se consagra la obligación de explotación de la patente.

Respecto de estos dos incorporales industriales las entidades estatales pueden ser titulares de verdaderos derechos de propiedad intelectual. Por ejemplo, la Nación-Ministerio de Comercio, Industria y Turismo es reconocida como titular de la marca "Vive Colombia" ${ }^{36}$, el Ministerio de Defensa tiene en trámite de registro una patente de invención ${ }^{37}$, la sociedad de economía mixta Ecopetrol S.A. es propietaria de un importan-

\footnotetext{
36 Que distingue instrumentos náuticos, cinematográficos, ópticos, papel, vestidos, sombreros, paraguas, sombrillas, entre otros. Los certificados tienen los siguientes números: 269615-269624.

37 Intitulada: Sistema de amarre en los muros de conexión (exp. 7 103347). Disponible en http://200.91.231.200/ oparra/externas/datospatente.php.
} 
te número de signos marcarios ${ }^{38}$ y patentes de CONCLUSIONES invención ${ }^{39}$.

De igual manera, Empresas Públicas de Medellín, empresa industrial y comercial del Estado, es titular de más de 24 signos distintivos. ${ }^{40}$

Asimismo, el artículo 29 de Ley 1450 de 2011 establece las mismas reglas de presunción de titularidad de derechos sobre propiedad industrial en cabeza del empleador o del encargante de la obra: "Salvo pacto en contrario, los derechos de propiedad industrial generados en virtud de un contrato de prestación de servicios o de trabajo se presumen transferidos a favor del contratante o del empleador respectivamente. Para que opere esta presunción se requiere que el contrato respectivo conste por escrito". Esta situación la podríamos extender de igual forma a los organismos estatales.

38 Marcas que distinguen petróleo crudo, combustibles, aceites y grasas industriales, lubricantes, materias de alumbrado y productos químicos destinados a la industria, ciencia, fotografía, agricultura, horticultura y silvicultura, entre otros. Certificados de la Superintendencia de Industria y Comercio, con los siguientes números: 350020, 350021, 216997, 216996, 350022, 350023, 350024, 350025, 350026, 350027, 350028, 350029, 350030, 350031, 350032, 350033, entre otros. Información disponible en: http://serviciospub.sic.gov.co/Sic/Propiedadlndustrial/ SignosDistintivos/Reportes/ConsultaSignos.php

Ecopetrol es propietaria de más de 31 patentes de invención, entre las cuales se destacan las siguientes: diseño de matriz en acero para la inyección de recipientes plásticos (exp. 92323013), herramienta desarenadora de pozos (exp. 9443233), herramienta para el retiro seguro de válvulas instaladas en tuberías de fluidos (exp. 6123320), proceso de producción de trampas de vanadio por impregnación y trampa de vanadio producida por dicho proceso (exp. 6 123231), proceso para la biodegradación de fenoles de aguas provenientes de tratamientos en la industria petrolera (exp. 97 48663). Véase: http://200.91.231.203/ Patentes/

40 Que distinguen servicios de acueducto, energía, gas, telecomunicaciones, explotación de datos matemáticos, por un lado, y bienes como vestidos, calzado y sombreros, por otro. Certificados de la Superintendencia de Industria y Comercio, con los siguientes números: 354837,351291 , 351292, 357619, 357420, 357421, 357422, 357423, entre otros. Información disponible en: http://serviciospub.sic.gov.co/ Sic/Propiedadlndustrial/SignosDistintivos/Reportes/ConsultaSignos. php
La propiedad es un derecho real. En esta medida, ofrece a su titular un haz de poderes directos sobre un bien. A más del modelo de propiedad singular, clásica u ortodoxa (arts. 669 - 673 $\mathrm{CC})$, se pueden reconocer en nuestra normativa algunas clases de propiedad que presentan ciertas particularidades respecto del régimen general. Piénsese en la nuda propiedad -desprovista temporalmente del ius utendi y el ius fruendi-, la propiedad de las entidades fiduciarias -sometida a un término y acompañada de una serie de vínculos obligacionales-, la copropiedad -que ofrece la titularidad del derecho a varias personas-, la propiedad horizontal -que engloba los regímenes de propiedad singular y copropiedad-, etc. Pues bien, el derecho de propiedad estatal intelectual puede considerarse doblemente especial: es intelectual y estatal.

\section{Primero, la propiedad intelectual se reconoce} sobre bienes o cosas incorporales, bienes que no están dotados de materia y, por ello, no ocupan espacio físico alguno. ${ }^{41}$ Se trata de construcciones del intelecto que, a través de distintas herramientas, reportan beneficios sociales,

41 Ahora bien, con la denominada "cosificación de los derechos", parece cometerse un grave yerro: se asume que los bienes incorporales son los derechos patrimoniales (arts. 653 y $664 \mathrm{CC}$ ). Es decir, se propone que los bienes incorporales -los derechos patrimoniales- se reconocen respecto de los bienes materiales. Téngase claro que los bienes o cosas son los objetos de los derechos patrimoniales. Precisamente, la expresión derecho patrimonial significa antes que todo una permisión sobre un bien. En una palabra, "cosa es la referencia objetiva del derecho subjetivo." Biondi, B. (2003). Los bienes. Barcelona: Bosh, p. 25. Trad. Martínez Radio. Igualmente, véase: Hohfeld, W. N. (1997). Conceptos jurídicos fundamentales. México: Fontamara. Col. BÉFDP, México. Trad. Genaro Carrió, pp. 50- 67 y Ross, A. (1997). Sobre el derecho y la justicia. Buenos Aires: Eudeba. Trad. Genaro Carrió, pp. 201- 205. 
espirituales y económicos al hombre. ${ }^{42}$ En una palabra, como los bienes materiales, los incorporales "cumplen con los requisitos de prestarle una utilidad a un sujeto o ente de derechos". ${ }^{43}$

Segundo, se trata de una propiedad ofrecida a las entidades estatales. Hablamos de la nación, departamentos, municipios, distritos, áreas metropolitanas, establecimientos públicos, unidades administrativas especiales, sociedades de economía mixta, empresas industriales y comerciales de los entes regionales, corporaciones autónomas regionales, empresas sociales del Estado, empresas oficiales de servicios públicos domiciliarios, instituciones financieras nacionalizadas, entre otras. ${ }^{44}$

Desde luego se habla de una propiedad muy especial. El Estado, diferenciándose de cualquier otro dominus, tiene por fines servir a la comunidad; promover la prosperidad general; garantizar la efectividad de los principios, derechos y deberes de las personas en general; mantener la integridad del territorio y del orden justo, etc. (art. $2 \mathrm{CN}$ ). No obstante, aclaramos que la tradicional división de propiedad estatal sobre los bienes materiales, dominio público y privado estatal, no se reconoce respecto de los bienes incorporales. En nuestra normativa, exclusivamente, se ofrece un dominio privado intelectual

42 Véase: Gómez, J. A. (1974). El secreto industrial, concepto y protección. Madrid: Tecnos, p. 73. Igualmente: Metke, R. (2001). Lecciones de Propiedad Industrial. Medellín: Biblioteca Jurídica Diké, p. 20.

43 León Robayo, E. (2006). La posesión de los bienes inmateriales. Revista de Derecho Privado. Bogotá: Universidad de los Andes, t. 36, p. 85.

44

Véase: Rodríguez, Libardo. Derecho Administrativo. 14 ed., Bogotá: Temis, 2005, p. 45 y 46 . estatal. No se consagra pues una verdadera propiedad pública intelectual estatal.

Para terminar, vemos cómo la palabra "propiedad" puede recibirse como un "fenómeno que se desarrolla con una fuerza irresistible". ${ }^{45}$ No hay entonces en la sociedad colombiana un único derecho de propiedad, sino múltiples propiedades. En este vasto grupo englobamos un régimen especial relacionado con los incorporales estatales.

\section{Bibliografía}

Acuerdo sobre Patentes y Privilegios de Invención (Ley 18 de 1913).

OMPI. Acuerdo sobre los Aspectos de los Derechos de Propiedad Intelectual Relacionados con el Comercio (Ley 170 de 1994).

Anónimo. (2000). Copyright-visual Artists Rights Act. Harvard Law Review, t. 109, $\mathrm{n}^{\circ}$ 8, p. 2110.

Biondi, B. (2003). Los bienes. Barcelona: Bosh, p. 25. Trad. Martínez Radio.

CAN.

Decisión 351 de 1993.

Decisión 486 de 2000.

45

Josserand, L. (1940). Configuration du droite de propriété d'un ordre juridique nouveau. Melanges dédiés a M. le professeur Sugiyama. Tokio: Librairie du Recueil, p. 95 y 96. 
Colombia.

Código Civil.

Consejo de Estado. Sala de Consulta y Servicio Civil. Sentencia del 5 de diciembre de 2002. Rad. 1469.

Consejo de Estado. Sala de lo Contencioso Administrativo. Sección Primera. Sentencia del 12 de mayo de 1995. Rad.3158. M.P. Rafael Ariza M.

Consejo de Estado. Sala de lo Contencioso Administrativo. Sección Primera. Sentencia del 6 de febrero de 2003. Rad. 58045. M.P. Olga Inés Navarrete Barrero.

Consejo de Estado. Sala de lo Contencioso Administrativo. Sección Cuarta. Sentencia del 8 de mayo de 2008. Exp. 15448. M.P. Héctor Romero D.

Consejo de Estado. Sala de lo Contencioso Administrativo. Sección Primera. Sentencia del 6 de julio de 2000. Exp. 5303. M.P. Juan Alberto Polo.

Consejo de Estado. Sala de lo Contencioso Administrativo. Sentencia del 6 de febrero de 2003. M.P. Olga Inés Navarrete Barrero.

Consejo de Estado. Sala de lo Contencioso Administrativo. Sección Primera. Sentencia del 6 de febrero de 2003. Rad. 58045. M.P. Olga Inés Navarrete Barrero.

Consejo de Estado. Sala de Contencioso Administrativo. Sección Primera. Sentencia del 16 de noviembre de 2000. M.P. Olga Inés Navarrete Barrero.

Consejo de Estado. Sala de lo Contencioso Administrativo. Sección Primera. Sentencia del 3 de agosto de 2000. Rad. 6264. M.P. Juan Alberto Polo F.

Consejo de Estado. Sala de lo Contencioso Administrativo. Sección Tercera. Sentencia del 22 de junio de 2006. Exp. 25000-2327-000-2003-02077-01. M.P. María Elena Giraldo G.

Consejo de Estado. Sala de lo Contencioso Administrativo. Sección Primera. Sentencia del 23 de marzo de 2000. Rad. 5504. M.P. Manuel Urueta.

Corte Constitucional. Sentencia T- 50 de 1995. M.P. Alejandro Martínez Caballero.

Corte Constitucional. Sentencia C-189 de 2006. M.P. Rodrigo Escobar G.

Corte Constitucional. Sentencia T-150 de 1995. M.P. Alejandro Martínez C.

Corte Constitucional. Sentencia C-189 de 2006. M.P. Rodrigo Escobar G.

Corte Constitucional. Sentencia C-668 de 2005. M.P. Álvaro Tafur G.

Corte Constitucional. Corte Constitucional. Sentencia T-490 de 1999. M.P. Vladimiro Naranjo M. 
Corte Constitucional. Sentencia C-276 de 1996. M.P. Julio César Ortiz G.

Corte Constitucional. Sentencia C-276 de 1996. M.P. Julio César Ortiz G.

Corte Constitucional. Sentencia T-938 de 2004. M.P. Eduardo Montealegre L.

Corte Suprema de Justicia. Casación Civil. Sentencia del 14 de junio de 1988. Jurisprudencia y doctrina, t. XVII, $n^{\circ} 200$, agosto de 1988.

Corte Suprema de Justicia. Casación Civil. Sentencia del 26 de abril de 1995, G.J, n $^{\circ}$ 26.

Corte Suprema de Justicia. Casación Civil. Sentencia del 29 de julio de 1999, exp. 5074, M.P. Jorge A. Castillo R.

Ley 6 de 1970. Aprueba la Convención Interamericana sobre el Derecho de Autor en Obras Literarias, Científicas y Artísticas.

Ley 33 de 1987. Aprueba el Convenio de Berna para la Protección de las Obras Literarias y Artísticas.

Ley 178 de 1994. Aprueba el Convenio de París para la Protección de la Propiedad Industrial.

Ley 165 de 1994. Aprueba el Convenio sobre la Diversidad Biológica.

Ley 33 de 1920. Sobre adopción del Himno Nacional.
Ley 23 de 1982 sobre derechos de autor

Ley 1450 del 16 de junio de 2011.

George, H. (1922). La ciencia de la economía política. Traducido por Baldomero Argente. Madrid: Librería española y extranjera, $\mathrm{p}$. 167.

Gómez, J. A. (1974). El secreto industrial, concepto y protección. Madrid: Tecnos, p. 73.

Hohfeld, W. N. (1997). Conceptos jurídicos fundamentales. México: Fontamara. Col. BÉFDP, México. Trad. Genaro Carrió, pp. 50- 67.

Josserand, L. (1940). Configuration du droite de propriété d'un ordre juridique nouveau. Melanges dédiés a M. le professeur Sugiyama. Tokio: Librairie du Recueil, p. 95 y 96.

Lasarte, C. (2010). Propiedad y derechos reales de goce. Madrid: Marcial Pons, p. 232.

León Robayo, E. (2006). La posesión de los bienes inmateriales. Revista de Derecho Privado. Bogotá: Universidad de los Andes, t. 36, p. 85.

Metke, R. (2001). Lecciones de Propiedad Industrial. Medellín: Biblioteca Jurídica Diké, p. 20.

Rengifo, E. (2003). Propiedad intelectual. El moderno derecho de autor. Bogotá: Universidad Externado, p. 128.

Rodríguez, L. (2005). Derecho Administrativo. Bogotá: Temis, pp. 45-46 
Ross, A. (1997). Sobre el derecho y la justicia. Tribunal Supremo de España. Sentencia del 1 Buenos Aires: Eudeba. Trad. Genaro Carrió, de febrero de 2005. Colección de propiedad pp. 201- 205. intelectual. Madrid: Reus S.A., 2006, pp. 271 yss.

The Statute of Anne. Disponible en: <http:// www.copyrighthistory.com/anne.html>

Villey, M. (2006). La formation de la pensée juridique moderne. Paris: PUF, 2006, pp. 229 y ss. 